\title{
ERRATUM
}

The correct title of the paper published in the Journal of Radioanalytical and Nuclear Chemistry, Articles, Vol. 168 , No. 2 (1993) $307-315$ is as follows:

\section{CHEMICAL ANALYSIS OF ARCHAEOLOGICAL COPPER AND BRASS FROM NORTHEASTERN ONTARIO}

\author{
R. G. V. HANCOCK, ${ }^{*}$ W. A. FOX, ${ }^{* *}$ T. CONWAY, ${ }^{* *}$ L. A. PAVLISH ${ }^{* * *}$ \\ *SLOWPOKE Reactor Facility and Department of Chemical Engineering and Applied Chemistry, \\ University of Toronto, Toronto, MSS 1A4 (Canada) \\ **Heritage Branch, Ontario Ministry of Culture and Communications, Toronto, M7A 2R9 (Canada) \\ ***Department of Physics, University of Toronto, Toronto, M5S IA7 (Canada)
}

Additionally on page 309, 4 lines from the bottom, " $\mathrm{Au}(>60 \mathrm{ppm}$ )" should read " $\mathrm{Au}$ ( $>60 \mathrm{ppb}$ )". 